\title{
ECONOMIC ENTITIES IN THE CONTEXT OF TECHNOLOGICAL MODERNIZATION OF ECONOMY: PRIORITY TRENDS TAKING INTO ACCOUNT DIGITAL TRANSFORMATION ${ }^{1}$
}

\author{
Anna V. Shkalenko \\ Volgograd State University, Volgograd, Russian Federation \\ Yulia A. Tymchuk \\ Volgograd State University, Volgograd, Russian Federation
}

\begin{abstract}
The basis of this study is the use of elements of an innovative methodology of post-institutional analysis based on the interdisciplinary synthesis, which involves overcoming the monodimensionality, dichotomization and dogmatism of many concepts of orthodox neo-institutionalism. The main idea of this study is to apply an interdisciplinary approach to study the impact of technological modernization on economic entities and identify priority trends taking into account digital transformation of public relations. The assessment of the current problems under study and the conceptual framework of the study were carried out on the basis of studying and rethinking the results of numerous works by European and Russian scientists, as well as the legislation of the Russian Federation. The regulatory framework covers current domestic legislation in the field of civil, business and tax law, which regulates innovative activities. As a result of the conducted research, it is established that innovative activity is managed by a large number of regulations of various industry affiliation, which do not have any systemic connection with each other. The existing terminological intricacy is revealed in innovation legislation. The current legislation, including at the level of the constituent entities of the Russian Federation, does not set the criteria and the indicators of an innovative organization. This serves as a factor that both complicates obtaining state support and hinders the wider introduction of innovations. The mechanisms of stimulating innovative activity provided by the tax legislation are investigated, and their effectiveness is also evaluated. The article proves the need for तิ adoption of a special Federal Law aimed at regulating innovative legal relations. The need to improve the tax त legislation is justified in terms of creating a special tax regime for subjects of innovative activity. It is proposed to $<$ expand the measures of state support for innovation activity within the subjects in the Russian Federation by introducing the institute of innovation voucher. The role of responsible innovations for sustainable business development in the period of digital transformation of society is defined.

Key words: responsible innovations, economic entities, technological modernization, digital transformation, industrial policy, innovative state development.

Citation. Shkalenko A.V., Tymchuk Yu.A. Economic Entities in the Context of Technological Modernization of Economy: Priority Trends Taking into Account Digital Transformation. Vestnik Volgogradskogo gosudarstvennogo universiteta. Ekonomika [Journal of Volgograd State University. Economics], 2020, vol. 22, no. 4, pp. 74-87. (in Russian). DOI: https://doi.org/10.15688/ek.jvolsu.2020.4.7
\end{abstract}




\title{
ХОЗЯЙСТВЕННЫЕ СУБЬЕКТЫ \\ В УСЛОВИЯХ ТЕХНОЛОГИЧЕСКОЙ МОДЕРНИЗАЦИИ ЭКОНОМИКИ: ПРИОРИТЕТНЫЕ НАПРАВЛЕНИЯ ИЗМЕНЕНИЙ С УЧЕТОМ ЦИФРОВОЙ ТРАНСФОРМАЦИИ ${ }^{1}$
}

\author{
Анна Викторовна Шкаленко \\ Волгоградский государственный университет, г. Волгоград, Российская Федерация \\ Юлия Александровна Тымчук \\ Волгоградский государственный университет, г. Волгоград, Российская Федерация
}

\begin{abstract}
Аннотация. Данное исследование базируется на использовании элементов инновационной методологии постинституционального анализа на основе междисциплинарного синтеза, которая предполагает преодоление моноаспектности, дихотомичности и догматизма многих концепций ортодоксального неоинституционализма. Основная идея данного исследования заключается в том, что используется междисциплинарный подход к изучению влияния технологической модернизации на хозяйствующие субъекты и определения приоритетных направлений с учетом цифровой трансформации общественных отношений. Оценка современного состояния исследуемой проблемы и формирование концептуальных рамок исследования были осуществлены на основе изучения и переосмысления результатов многочисленных работ зарубежных и российских ученых, а также законодательства РФ. Нормативно-правовой основой работы выступает действующее отечественное законодательство в сфере гражданского, предпринимательского и налогового права, регламентирующее инновационную деятельность. В результате проведенного исследования установлено, что инновационная деятельность регулируется большим массивом нормативных актов различной отраслевой принадлежности, которые не имеют какой-либо системной связи друг с другом. Выявлена существующая терминологическая проблема инновационного законодательства. В действующем законодательстве, в том числе на уровне субъектов РФ, также не закреплены критерии инновационной деятельности и признаки инновационной организации, что является фактором как затрудняющим получение государственной поддержки, так и препятствующим более широкому внедрению инноваций. Исследованы механизмы стимулирования инновационной деятельности, предусмотренные налоговым законодательством, проведена оценка их эффективности и доказана необходимость принятия специального федерального закона, направленного на урегулирование инновационных правоотношений. Обоснована потребность в совершенствовании налогового законодательства в части создания специального режима налогообложения для субъектов инновационной деятельности. Предложено расширить спектр мер государственной поддержки инновационной активности субъектов за счет введения института инновационного ваучера. Определена роль ответственных инноваций для устойчивого развития бизнеса в период цифровой трансформации общества.

Ключевые слова: ответственные инновации, хозяйствующие субъекты, технологическая модернизация, цифровая трансформация, промышленная политика, инновационное развитие государства.
\end{abstract}

Цитирование. Шкаленко А. В., Тымчук Ю. А. Хозяйственные субъекты в условиях технологической модернизации экономики: приоритетные направления изменений с учетом цифровой трансформации // Вестник Волгоградского государственного университета. Экономика. - 2020. - Т. 22, № 4. C. 74-87. - DOI: https://doi.org/10.15688/ek.jvolsu.2020.4.7

\section{Введение}

В условиях глобального кризиса экономической системы и высокого уровня неопределенности, спровоцированного масштабной цифровой трансформацией общественных и экономических отношений и усугубленного наступлением пандемии COVID-19, резко возрастает роль модернизации отраслей промышленности, которая направлена на повышение эффективности организационно-экономического уровня деятельности хозяйственных субъектов в интересах национальной экономики и повышения конкурентоспособности отечественных предприятий на мировом рынке. Для этого на государственном уровне 
прорабатываются и внедряются различные традиционные меры, а также новые технологические решения, основанные на технологиях Индустрии 4.0.

Модернизация промышленной политики направлена на снижение уровня неуверенности предприятий в спонтанной рыночной среде и повышение их способности адаптироваться к высокой турбулентности в деловой среде. В условиях сложной макроэкономической ситуации и обострения в связи с этим различных негативных процессов на внутреннем рынке РФ большая часть отечественных субъектов предпринимательской деятельности не готова внедрять в свою деятельность новые инновационные технологии, применение которых позволило бы создавать конкурентоспособную, в том числе на мировом рынке, продукцию [Яковлев и др., 2020]. Данная тенденция подтверждается и количественными значениями основных параметров, отражающих состояние инновационной деятельности в РФ [Меленкин, 2016].

Вместе с тем для решения ряда крупных для нашей страны проблем, в числе которых как обеспечение продовольственной безопасности, так и минимизация уровня сырьевой зависимости отечественной экономики, требуется ускоренное внедрение инновационных технологий с параллельным развитием инновационной инфраструктуры. При этом важно отметить, что реализация обозначенных мероприятий невозможна без соответствующего нормативного регулирования, способного обеспечить переход национальной экономики с ее ярко выраженной сырьевой направленностью к экономике новой модели развития.

\section{Новые меры со стороны государства и ответственные инновации со стороны бизнеса}

На сегодняшний день государство выполняет координирующую роль с позиции повышения эффективности производств, генерирующих высокий уровень развития в соответствии с социально-экономическими интересами России. В условиях экономического кризиса как в нашей стране, так и во всем мире существует много неопределенностей относи- тельно прогнозов глобального экономического развития, целей научно-технического развития перед лицом вызовов Индустрии 4.0.

Основные теории, сформированные в результате анализа последовательного развития за последние несколько десятилетий, вращаются вокруг трех фундаментальных положений, касающихся: 1) роли и структурных взаимозависимостей секторов экономики, сопряжения процессов акторов, возникающих в условиях индустриализации; 2) необходимости гармонизации экономической политики ряда институтов, продвигающих промышленную повестку дня; 3) признания роли государства в управлении экономической политикой, его мер политики в сочетании с его предпринимательской функцией.

Большинство авторов, занимающихся исследованием данных вопросов, подтверждают дискуссионный характер современных концепций промышленной политики в разных странах. Научное сообщество подчеркивает необходимость стратегической координации интерактивных мер промышленной политики, согласованного взаимодействия управленческих структур на уровне национальной экономики [Andreoni et al., 2019б, p. 136-150].

Работа А. Андреони, Х.-Дж. Чанга и Р. Скацциери указывает на необходимость обновления повестки дня для обсуждения содержания и формы промышленной политики с упором на установление взаимоотношений между структурами, учреждениями и политиками. Следует учитывать исторические традиции производственных отношений, аспекты производственных, технических и рыночных отношений, а также политическую экономию. Предлагается рассматривать промышленную политику в более широком аспекте, в рамках целостной структуры социально-экономических и политических отношений общества [Andreoni et al., 2019a, p. 1-6].

Исчерпание чисто рыночных механизмов и моделей приоритетной организации производств с высокой добавленной стоимостью требует выявления новых способов стимулирования деловой активности промышленников и предпринимателей на основе целенаправленной политики, обеспечивающей четкие и стабильные условия работы на горизонте планирования от трех до пяти лет. В глобальной 
экономике взаимозависимость фирм в отдельных странах стала сильной. Звенья единой трансграничной цепочки создания стоимости, скачки неопределенности для них более синхронизированы за счет общей динамики производства и потребления, инструментов регулирования. В таких крупных интеграционных образованиях, как Европейское сообщество, НАФТА, МЕРКОСУР, а также Евразийский экономический союз (ЕАЭС). Представители власти и бизнеса должны понимать суть изменений, развивать новые направления трансформации экономических отношений, повышать компетенции, внедрять методы организации производства и менять законодательство в соответствии с новыми требованиями функционирования экономической системы и хозяйствующих субъектов.

Данная тенденция играет ключевую роль, но существуют и непредвиденные глобальные факторы, такие как, например, пандемия COVID-19, провоцирующие неопределенность во всем мире, из-за которых происходят изменения как во внутреннем производственном цикле, так и глобальных цепочках создания стоимости, ослабляя производственные связи, особенно в менее развитых странах мира, которые не имеют высокого научно-технического потенциала. Чтобы избежать особенно негативного сценария падения ВВП из-за потери места в глобальных цепочках создания стоимости, национальным экономикам необходимо переключиться на политику импортозамещения и увеличить внутреннее потребление, что будет способствовать экономическому развитию и установит новый экономический порядок с использованием решений государственной политики.

Несмотря на большую разницу в подходах, все они имеют общие характеристики: 1) потребность во влиянии государства, определенная в той или иной форме; 2) выделение определенной системы приоритезации либо в отраслевом разрезе, либо для отдельных функций хозяйственного механизма; 3) ориентация на долгосрочную (стратегическую) перспективу; 4) комплексность, то есть охват широкого спектра мероприятий и направлений деятельности.

С одной стороны, в макроэкономическом плане грамотная промышленная политика за счет перераспределения ресурсов и возврата материнских компаний на территорию национальной экономики сможет сократить риски для крупных корпораций. С другой стороны, «обратное втягивание» производственных и технологических линий транснациональных корпораций в их национальные границы отрицательно скажется на промышленном облике регионов - их прежних местонахождений, в основном в странах с развивающейся экономикой. В дополнение к этому в контексте повсеместной цифровой трансформации предыдущая политика перемещения производства добавленной стоимости в страны с дешевой рабочей силой (Азия, Латинская Америка).

Определения инноваций различаются по масштабам новизны. В то время как А. Кизер определяет инновации как новшество на уровне организации [Kieser, 1969], согласно Б. Ведину, инновация - это «...изобретение, впервые примененное, первое появление на рынке» [Vedin, 1980, с. 22]. Р. Гарсия и Р. Калантоне определяют шесть перспектив новизны в современной литературе по инновациям: новинка для компании, новинка для принимающего подразделения, новинка на рынке, новинка в отрасли, новинка для потребителя и новинка для мира [Garcia et al., 2002].

История инноваций берет начало в исследованиях экономиста Йозефа Шумпетера (1883-1950) и уходит своими корнями в социально-экономическую теорию. Для Й. Шумпетера экономическое развитие было динамичным процессом, движимым развитием новых комбинаций - инноваций, которые в процессе созидательного разрушения порождают новые бизнес-модели [Schumpeter, 1939]. Инновация может возникнуть в форме нового продукта, ранее неизвестного потребителю, но также в форме нового качества существующего продукта. Точно так же инновации могут возникать в виде внедрения нового метода производства, открытия новых рынков сбыта, развития новых источников сырья или реорганизации бизнеса, уже существующего на рынке. В любой форме инновации позволяют предприятиям занимать временное монопольное положение, которое длится до тех пор, пока конкурирующиепредприятия либо успешно имитируют инновации, либо не добьются 
превосходства за счет дальнейших или новых разработок.

С экономической точки зрения инновации обычно рассматриваются как основа конкурентоспособной экономики [Adams et al., 2006] и, следовательно, как нечто, что по своей сути желательно в нынешнем восприятии западного индустриального мира [Blok et al., 2015; Moldaschl, 2010]. Компании стремятся к инновациям, чтобы осваивать новые сегменты рынка, улучшать качество своей продукции или сокращать производственные затраты. Они стараются сохранить свое конкурентное преимущество или улучшить свое положение на рынке с помощью инновационных продуктов (товаров и услуг), инновационных процессов (методов производства или доставки), инновационного маркетинга (дизайн, упаковка, размещение, продвижение, ценообразование) или организационных инноваций (бизнес-практики, организация рабочего места, внешние связи). В этой постоянной гонке за новинками и улучшениями могут победить только те, кто постоянно изобретает себя и свою продукцию. Однако успех инновации измеряется с точки зрения ее распространения на рынке и получения экономической прибыли для владельца инновации. Социальная выгода может возникать как положительные внешние эффекты инноваций, но сами по себе они не являются решающими для действий. Таким образом, инновации могут быть источником дохода для владельца инноваций и в то же время приводить к потере рабочих мест или вызывать краткосрочные или долгосрочные проблемы с окружающей средой, здоровьем или безопасностью, которые могут или не могут стать очевидными во время вывода инновации на рынок. Этот факт нашел свое противодействие в подходах к замене решений на рынке более экологичными, более устойчивыми или более социально желательными, и таким образом объединилось стремление к конкурентоспособности с нормативным требованием по снижению вреда для людей и окружающей среды.

Управление инновациями в компаниях в основном связано с созданием благоприятной среды для новых идей и принятием решения, какие из них будут развиваться дальше, а от каких следует отказаться. Это означает, что не каждая новая идея обязательно превратится в инновации или приведет к ним. Это также означает, что менеджмент инноваций постоянно занимается созданием возможностей для инноваций посредством формулирования новых идей и уничтожением возможностей для инноваций, отбрасывая значительную часть этих идей до того, как они достигнут рынка, или даже на этапе разработки. В литературе по менеджменту широко обсуждаются подходы к созданию инновационной культуры в организации, плюсы и минусы привлечения внешних участников компании и процесс выбора одной идеи по сравнению с другой. Эти обсуждения слишком разносторонни, чтобы их можно было воспроизвести в данной работе. Однако следует отметить, что решения о реализации одной идеи и отказе от другой обычно принимаются при высоком уровне неопределенности в отношении потенциального успеха. Чем выше динамика на конкретном рынке и чем радикальнее нововведение, тем выше будет уровень неопределенности. Хорошо известные управленческие подходы к снижению неопределенности за счет использования информации из внешних источников компании включают открытые инновации, пользовательские инновации и инновационные сообщества [Fichter, 2009; Open Innovation ..., 2006; Gassmann et al., 2004; Индикаторы инновационной деятельности ..., 2019].

Сегодня определения ключевых терминов, таких как «инновация» и «инновационная деятельность», закреплены на уровне федерального законодательства, в частности в ст. 2 Закона № 127-Ф3. До закрепления в 2011 г. определений понятий «инновации» и «инновационная деятельность» на федеральном уровне для установления их содержания требовалось обращаться к Концепции инновационной политики Российской Федерации на 19982000 гг. [Постановление Правительства РФ от 24.07.1998 № 832 ...] или к Основным направлениям политики Российской Федерации в области развития инновационной системы на период до 2010 г. [Основные направления политики ..., 2005].

Между тем в правовой и экономической доктрине продолжаются дискуссии по вопросу об их сущности и содержании [Городов, 2012; Ефимцева, 2012; Костенко, 2012; 
Пашкова, 2017; Степаненко, 2012; Табурчак и др., 2018]. Оправданность имеющихся научных дискуссий подтверждается размытостью формулировок определений «инновация» и «инновационная деятельность», закрепленных в ст. 2 Закона № 127-ФЗ.

Отдельного внимания заслуживает и анализ определения понятия «инновационная инфраструктура».

Представляется, что закрепленная в Законе № 127-Ф3 редакция обозначенного определения в совокупности с определением понятия «инновационная деятельность» является некорректной, поскольку деятельность по созданию инновационной инфраструктуры отнесена законом к инновационной. Некоторые исследователи полагают, что законодателем был принят такой подход намеренно [Предпринимательское право ..., 2017].

К числу недостатков определения, по нашему мнению, возможно отнести и отсутствие законодательно закрепленного определения термина «услуги (управленческие, материально-технические, финансовые, информационные, кадровые, консультационные и организационные), содействующие инновационной инфраструктуре». Данные обстоятельства приводят к тому, что, в частности, идентичная финансовая или информационная услуга, которая предоставляется заинтересованным субъектам, будет иметь различные правовые последствия, поскольку в одном случае (при оказании услуги субъекту, который не реализует инновационный проект) налогообложение доходов, полученных от оказания услуг, будет осуществляться на общих основаниях, а в другом случае (при оказании услуги субъекту, который реализует инновационный проект) такая деятельность будет признаваться инновационной и ее налогообложение будет осуществляться на льготных условиях.

В нормативно-правовых актах возможно встретить термины, которые, на наш взгляд, соотносятся с термином «инновационная инфраструктура», как целое и его часть. Полагаем, что такое обилие терминологии в части определения основных субъектов, задействованных в реализации государственной инновационной политики, не совсем удачно, поскольку отсутствие целостного понятийно- го аппарата может негативно повлиять на эффективность правоприменения.

Кроме того, анализ нормативной базы инновационной деятельности в России позволил также прийти к выводу об отсутствии достаточных правовых условий для ее развития. Несмотря на наличие многочисленных нормативных актов, утверждать, что в совокупности они образуют стройную, логичную, взаимосвязанную систему, не представляется возможным. Напротив, наблюдается явная изолированность хоть и относящихся к различным отраслям права нормативных положений, но направленных на урегулирование общественных отношений, так или иначе связанных с инновационной деятельностью.

На наш взгляд, отсутствие системного подхода к правовому регулированию инновационной деятельности, наряду с иными конкретными проблемами, которые возможно обнаружить после анализа вышеперечисленных нормативно-правовых актов, является одним из факторов, неблагоприятно влияющим на построение конкурентоспобной экономики и реализацию государственной политики по импортозамещению.

Потребность в применении системного подхода к правовому регулированию инновационной деятельности обусловлена и спецификой ее сущности. Кроме того, необходимо обратить внимание и на комплексность инновационного права как отрасли законодательства.

В целях иллюстрации вышеизложенных обстоятельств обратимся к анализу действующих налоговых механизмов стимулирования инновационной деятельности в России, поскольку, на наш взгляд, именно налоговое стимулирование выступает одним из ключевых драйверов инновационной экономики [Лайченкова, 2015]. Данный тезис подтверждается и зарубежной практикой [Клавдиенко, 2018; Куклина и др., 2013].

При оценке основных положений налогового законодательства, направленных на стимулирование инновационной деятельности, нельзя не согласиться с Ю.А. Крохиной, которая обоснованно подчеркивает, что такие налоги, как НДС и налог на прибыль организаций для предприятий, которые занимаются НИР илиОКР, на первых этапах инновационного 
процесса не столь обременительны для них и соответственно не имеют первостепенного значения [Крохина, 2012] с точки зрения затрат организации, поскольку фактически говорить о наличии объекта налогообложения преждевременно. Одновременно с этим основная финансовая нагрузка организации связана с выплатой заработной платы работникам, лицам, оказывающим услуги на основании заключенных гражданско-правовых договоров, уплатой страховых взносов во внебюджетные фонды и НДФЛ.

Необходимо отметить и то, что освобождение от уплаты НДС-операций, опосредующих оборот определенных видов объектов интеллектуальной собственности (пп. 26 п. 2 ст. 149 НК РФ), безусловно, необходимая мера, однако утверждать о ее направленности на стимулирование инновационной активности хозяйствующих субъектов, на наш взгляд, не представляется возможным, учитывая характер и процесс создания конкретного объекта интеллектуальной собственности. Полагаем, что данное законоположение направлено на содействие реализации одной из стадий инновационного процесса.

В дополнение к изложенному стимулирующий характер нормы, закрепленной в пп. 16.1, п. 3 ст. 149 НК РФ, также вызывает вопросы, поскольку в сущности ею охватывается лишь стадия инновационного процесса, заключающаяся в генерации и создании инновации.

В подобных условиях требуют пересмотра закрепленные в налоговом законодательстве подходы по стимулированию инновационной активности хозяйствующих субъектов с точки зрения стадий инновационного процесса и реальных потребностей хозяйствующих субъектов.

Некоторые из действующих положений налогового законодательства в рассматриваемой сфере, представляются непроработанными.

Закрепленное в пп. 7 п. 1 ст. 150 НК РФ, на наш взгляд, требует доработки ввиду того, что в действующей редакции правило фактически, с одной стороны, полностью противоречит реализуемой государственной политике по импортозамещению, а с другой - лишь усиливает экспортно-сырьевую направлен- ность отечественной экономики. Так, в частности, законоположение освобождает лиц, ввозящих на территорию страны технологическое оборудование (пп. 7 п. 1 ст. 150 НК РФ) [Постановление Правительства РФ от 30.04.2009 № 372 ...], аналоги которого отсутствуют в РФ. При этом правовых механизмов, направленных на поощрение и стимулирование создания собственных инноваций на базе такого оборудования, законодательством не предусматривается.

Кроме того, вызывает сомнения и эффективность с точки зрения реализации государственной политики по импортозамещению, в том числе посредством создания условий для активизации инновационной деятельности, института инвестиционного налогового кредита, поскольку, несмотря на его преимущества, организации так или иначе придется заплатить проценты за пользование денежными средствами, которые должны были быть уплачены в соответствующий бюджет, что в результате приведет лишь к увеличению издержек. В связи с этим представляется более целесообразным введение для субъектов, осуществляющих инновационную деятельность, такой налоговой льготы, как «налоговые каникулы» - налоговая ставка в размере $0 \%$ по конкретному налогу на несколько лет. При этом полагаем, что временной промежуток предоставления налоговых каникул должен быть дифференцирован в зависимости от конкретной отрасли экономики и продолжительности реализации инновационного процесса.

Рассмотренные правовые способы стимулирования инновационной активности, закрепленные в налоговом законодательстве, объединены общей целью, которая состоит в снижении затрат субъектов инновационной деятельности. При этом полагаем, что достижение такой цели затруднено несовершенством, заложенным в самой сущности проанализированных норм, которые сконструированы без учета реальных потребностей субъектов, осуществляющих инновационную деятельность.

Анализ мер налогового стимулирования и поддержки инновационной деятельности позволяет утверждать о наличии ярко выраженного субъектного критерия при решении вопроса об их предоставлении. В частности, на 
наш взгляд, в наиболее привилегированном положении находятся организации, получившие статус участника проекта по осуществлению исследований, разработок и коммерциализации их результатов в соответствии с Законом № 244-Ф3 или участника проекта согласно Закону № 216-Ф3, резидентов особых экономических зон.

С одной стороны, такой избирательный подход может выглядеть оправданным, а с другой - объективная необходимость в массовом внедрении инноваций, повышении инновационной активности организаций на территории всей страны как для целей реализации политики по импортозамещению, так и для решения комплексной проблемы по построению экономики нового типа, не обладающей экспортно-сырьевой направленностью, требует пересмотра избранного законодателем подхода.

Таким образом, несмотря на явное стремление отечественного законодателя оказывать поддержку инновационной деятельности, субъекты такой поддержки, как и соответствующий административно-правовой механизм ее оказания, не конкретизированы [Степаненко, 2016]. В последние годы в обществе возник сильный толчок к признанию того, что производственно-сбытовые цепочки предприятий от источников сырья до производства, продаж и окончательного срока службы продукции оказывают воздействие на людей и окружающую среду, за которые они несут ответственность. Таким образом, Европейская комиссия, а также другие государственные деятели изменили определение того, что означает КСО, с «добровольного вклада компании в общество» на «ответственность компании за ее влияние» на общество [European Commission ..., , 2011], включая людей и окружающую среду.

В связи с этим социальным давлением понимание и концептуализация ответственности компании перед обществом теперь охватывает ряд вопросов, тем и деловых операций. Компании из различных секторов подвергаются тщательной проверке на предмет их воздействия на людей и окружающую среду в рамках всей цепочки создания стоимости [Phillips et al., 2005]; распространение их ответственности за воздействие за пределы их собственных операций на цепочки поставок и использование продукции. Это включает в себя поиск материалов и закупку в цепочках поставок, производстве, транспортировке и упаковке и, наконец, эффекты жизненного цикла от фактического использования продукта, его утилизации или загробного существования. Вопросы варьируются от использования ресурсов окружающей среды или выбросов в воздух, землю или воду до воздействия на права человека, обеспечения достойной работы, здоровья и безопасности на производстве или деятельности компании, обеспечения экологически безопасного загробного существования продуктов компании или даже социальной желательности продуктов и услуг компании. Следовательно, ответственность бизнеса перед обществом теперь означает как ответственное управление бизнес-операциями, так и ответственность бизнеса за воздействие своих продуктов и услуг на людей и окружающую среду. Ожидается, что компании во всем мире возьмут на себя ответственность за непричинение вреда людям и окружающей среде, в то время как самые прогрессивные из них изучают стратегии, которые управляют бизнесом, реагируя на потребности общества.

\section{Заключение}

Полагаем, что в целях стимулирования инновационной активности хозяйствующих субъектов и для решения тем самым проблемы импортозамещения и перехода к построению экономики нового типа без экспортносырьевого уклона, требуется реализовать комплекс мер правового характера.

Среди них совершенствование налогового законодательства в части создания специального режима налогообложения для субъектов инновационной деятельности [Янковский, 2017]. Вместе с тем, прежде чем приступать к разработке конкретных предложений по данному направлению, на наш взгляд, требуется принятие специального федерального закона, регламентирующего инновационную деятельность [Болтанова, 2018; Демина, 2018; Лайченкова, 2015; Лапин, 2018], в котором возможно было закрепить понятийный аппарат, особенности правового положения инновационных 
организаций и иных субъектов инновационной инфраструктуры с учетом как отраслевых особенностей, так и стадий реализации инновационного проекта, разграничить основные полномочия государственных органов в рассматриваемой сфере и проч. Потребность в его принятии назрела давно, однако, несмотря на это, выдвигаемые законодательные инициативы отклоняются [Проект Федерального закона № 344994-5 ..., 2012].

Кроме того, при его разработке считаем целесообразным учесть как потенциал таких мер (направленных на реализацию государственной инновационной политики), венчурное инвестирование (предусмотрев соответственно специальную главу, посвященную его правовому урегулированию), так и зарубежный опыт в части расширения правовых способов стимулирования инновационной деятельности (например, инновационный ваучер). Так, одним из положительно зарекомендовавших себя способов стимулирования инновационной активности субъектов малого и среднего предпринимательства за рубежом является инновационный ваучер.

Ответственные инновации, хотя и родились в сфере государственной политики и на сегодняшний день приняты в основном исследовательскими институтами, в значительной степени дополняют широкую концепцию ответственности бизнеса перед обществом. С точки зрения процесса он позволяет распространить концепцию ответственного управления бизнесом на отделы исследований и разработок НИОКР и направляет предприятия в том, как сделать свои НИОКР более ответственными и отвечающими потребностям общества. Традиционные подходы к корпоративной социальной ответственности пока еще не рассматривают стадию НИОКР как решающую, в которой аспекты ответственности должны быть интегрированы и рассмотрены. Более того, с точки зрения результатов, фирмы, интенсивно занимающиеся инновациями и НИОКР, особенно те, чьи клиенты являются посредниками, а не те, кто будет использовать продукт или услугу, не часто задумывались о том, как их нововведения влияют на общество. Возможно, они изучали свои источники и производственный процесс, но обращали меньше внимания на то, какие последствия могут быть вызваны для людей или окружающей среды после использования их продуктов или услуг. В концепции RI эти соображения о воздействии на общество и о том, как лучше всего служить обществу, входят в функции НИОКР в компаниях. Эта концепция также является многообещающей с точки зрения решения основной бизнес-ответственности компаний в секторах, которые требуют инноваций.

Хотя сами по себе инновации не имеют нормативной ориентации, некоторые компании сделали частью своих стратегий или бизнесмоделей внедрение инноваций, чтобы уменьшить негативное воздействие своих продуктов или услуг на людей и/или окружающую среду. В качестве стратегии управления инновациями ответственные инновации можно понимать как меру по снижению рисков, связанных с неспособностью инноваций удовлетворить потребности потребителей, упущением потенциальных рынков, дорогостоящей адаптацией или откатом на поздних этапах инновационного процесса с одновременным увеличением общественного авторитета, легитимности и доверия к компании и ее инновационным продуктам или услугам. Все это способствует повышению конкурентоспособности инновационного бизнеса.

\section{ПРИМЕЧАНИЕ}

${ }^{1}$ Исследование выполнено при финансовой поддержке РНФ, проект № 18-78-10075 «Институциональное моделирование экономико-правового механизма неоиндустриализации на основе развития цифровой экономики РФ».

The reported study was funded by the Russian Science Foundation according to the research project no. 18-78-10075 "Institutional modeling of the economic and legal mechanisms of neoindustrialization based on the development of the Russian digital economy".

\section{СПИСОК ЛИТЕРАТУРЫ}

Болтанова, Е. С. Саморегулирование в инновационном развитии России / Е. С. Болтанова // Гражданское право. - 2018. - № 6. - С. 24-27.

Городов, О. А. Юридические аспекты понятий инновации и инновационной деятельности 
/ О. А. Городов // Интеллектуальная собственность. Промышленная собственность. 2012. - № 2. - C. 5-12.

Демина, М. А. Правовое регулирование научной и инновационной деятельности медицинских организаций / М. А. Демина // Актуальные проблемы российского права. - 2018. - № 11. C. 116-123.

Ефимцева, Т. В. Проблемы правового определения понятия инновационной деятельности / Т. В. Ефимцева // Государство и право. 2012. - № 12. - С. 91-95.

Индикаторы инновационной деятельности: 2019 : стат. сб. / Л. М. Гохберг [и др.] ; Нац. исслед. ун-т «Высшая школа экономики». - М. : НИУ ВШЭ, 2019. - $376 \mathrm{c.}$

Клавдиенко, В. П. Налоговое стимулирование инновационной активности предприятий в Китае / В. П. Клавдиенко // Общество и экономика. - № 7. - 2018. - С. 39-50.

Костенко, В. В. Понятие «инновации», «инновационная деятельность» в российском законодательстве / В. В. Костенко // Северо-Кавказский юридический вестник. - 2012. - № 1. C. $85-89$.

Крохина, Ю. А. Проблемы налогового регулирования государственно-частного партнерства в инновационной сфере / Ю. А. Крохина // Финансовое право. - 2012. - № 2. - С. 21-26.

Лайченкова, Н. Н. К вопросу о роли налогового законодательства в процессе построения инновационной экономики: основные пути совершенствования / Н. Н. Лайченкова // Ленинградский юридический журнал. - № 2 (40). 2015. - С. 216-223.

Лапин, А. В. Развитие национальной инновационной системы как обязательное условие технологических изменений и роста производства / А. В. Лапин // Административное и муниципальное право. - 2018. - № 4. С. $26-41$.

Меленкин, В. Л. Реализация политики импортозамещения как фактор активизации инновационных процессов на региональном уровне / В. Л. Меленкин // Экономика и экология территориальных образований. - № 3. 2016. - C. 116-121.

Налоговая политика стимулирования инновационной деятельности организаций в России и Китае: этапы разработки и проблемы реализации / Е. А. Куклина [и др.] // Управленческое консультирование. - № 6 (54). - 2013. C. $48-60$.

Основные направления бюджетной, налоговой и таможенно-тарифной политики на 2019 год и на плановый период 2020 и 2021 годов (утв. Мин- фином России, 02.10.2018) // Доступ из справ.правовой системы «КонсультантПлюс».

Пашкова, Д. А. К вопросу о понятии «инновация» в российском праве / Д. А. Пашкова // Вопросы экономики и права. - 2017. - № 108. C. 7-11.

Постановление Правительства РФ от 24.07.1998 № 832 «О Концепции инновационной политики Российской Федерации на 1998-2000 годы» // Российская газета. - 1998. - № 158 (19 авг).

Постановление Правительства РФ от 30.04.2009 № 372 «Об утверждении перечня технологического оборудования (в том числе комплектующих и запасных частей к нему), аналоги которого не производятся в Российской Федерации, ввоз которого на территорию Российской Федерации не подлежит обложению налогом на добавленную стоимость» // Доступ из справ.-правовой системы «КонсультантПлюс».

Предпринимательское право: Правовое сопровождение бизнеса : учебник для магистров / Р. Н. Аганина [и др.] ; отв. ред. И. В. Ершова. - М. : Проспект, 2017. - 848 с.

Проект Федерального закона № 344994-5 «Об инновационной деятельности в Российской Федерации» (ред., внесенная в ГД ФС РФ, текст по состоянию на 18.03.2010) // Доступ из справ.правовой системы «КонсультантПлюс».

Степаненко, Д. М. Термин «инновация» как категориальная основа совокупности взаимосвязанных понятий / Д. М. Степаненко // Наука Красноярья. - 2012. - Т. 1, № 1. - С. 65-74.

Степаненко, Ю. В. Перспективы административноправового регулирования научной деятельности в свете разрабатываемой Стратегии научно- технологического развития России на долгосрочный период / Ю. В. Степаненко //Административное право и процесс. 2016. - № 9. - С. 5-12.

Табурчак, А. П. Исследование сущности инновационной деятельности / А. П. Табурчак, А. Л. Зелезинский, Е. А. Кондрашова // Журнал правовых и экономических исследований. -2018. № 4. - C. 204-208.

Трофимов, С. В. О налоговых аспектах проблемы импортозамещения в реалиях действующего законодательства / С. В. Трофимов // Законодательство и экономика. -2015 . - № 9. - С. 35-40.

Яковлев, Г. И. Особенности формирования промышленной политики и предпринимательства в условиях роста глобальной неопределенности / Г. И. Яковлев, А. В. Стрельцов // Бизнес. Образование. Право. - 2020. - № 3 (52). - C. 112-117. 
Янковский, Р. М. Правовое регулирование государственной поддержки инноваций в Российской Федерации / Р. М. Янковский // Предпринимательское право. - 2017. - № 3. - С. 21-29.

Adams, R. Innovation Management Measurement. A Review / R. Adams, J. Bessant, R. Phelps // International Journal of Management Reviews. - 2006. - № 8 (1). - P. 21-47.

Andreoni, A. Industrial Policy in Context: Building Blocks for an Integrated and Comparative Political Economy Agenda / A. Andreoni, H.-J. Chang, R. Scazzieri // Struct. Change Econ. Dyn. - 2019a. - № 48. - P. 1-6.

Andreoni, A. The Political Economy of Industrial Policy: Structural Interdependencies, Policy Alignment and Conflict Management / A. Andreoni, H.-J. Chang// Struct. Change Econ. Dyn. -2019б.№48. - P. 136-150.

Blok, V. The Emerging Concept of Responsible Innovation. Three Reasons Why it is Questionable and Calls for a Radical Transformation of the Concept of Innovation / V. Blok, P. Lemmens ; ed. by B.-J. Koops [et al.]. - Responsible Innovation 2: Concepts, Approaches, and Applications. - Cham : Springer, 2015. - P. 19-35.

European Commission. Communication from the Commission to the European Parliament, the Council, the European Economic and Social Committee of the Regions: A Renewed EU Strategy 2011-2014 for Corporate Social Responsibility.-Brussels : [S. 1.], 2011.

Fichter, K. Innovation Communities: The Role of Networks ofPromoters in Open Innovation / K. Fichter// R\&D Management.-2009. - № 39 (4). - P. 357-371.

Garcia, R. A Critical Look at Technological Innovation Typology and Innovativeness Terminology: A Literature Review/R. Garcia, R. Calantone // Journal of Product Innovation Management. - 2002. - № 19 (2). - P. 110-132.

Gassmann, O. Towards a Theory of Open Innovation: Three Core Process Archetypes / O. Gassmann, E. Enkel. - Lissabon : R\&D Management Conference (RADMA), 2004. - P. 1-18.

Kieser, A. Innovationen / A. Kieser // Handwörterbuch der Organisation / hrsg. von E. Grochla. Poeschel : Stuttgart, 1969. - S. 741-750.

Moldaschl, M. Why Innovation Theories Make no Sense, Lehrstuhlpapiere / M. Moldaschl // Professur für Innovationsforschung und Nachhaltiges Ressourcenmanagement. -2010. - № 9.

Open Innovation: Researching a New Paradigm / ed. by H. Chesbrough, W. Vanhaverbeke, J. West. - Oxford : Oxford University Press, 2006.

Phillips, R. Value Chain Responsibility: A Farewell to Arm's Length / R. Phillips, C. B. Caldwell
// Business \& Society Review. - 2005. - № 110 (4). P. 345-370.

Schumpeter, J. A. Business Cycles: A Theoretical, Historical, and Statistical Analysis of the Capitalist Process / J. A. Schumpeter. - N. Y. : McGraw-Hill, 1939. -658 p.

Vedin, B. A. Large Company Organization and Radical Product Innovation / B. A. Vedin. - Lund : BrattInstitut für Neues Lernen, 1980.

\section{REFERENCES}

Boltanova E.S. Samoregulirovanie v innovacionnom razvitii Rossii [Self-Regulation in the Innovative Development of Russia]. Grazhdanskoe pravo [Civil Law], 2018, no. 6, pp. 24-27.

Gorodov O.A. Yuridicheskie aspekty ponyatij innovacii i innovacionnoj deyatel'nosti [Legal Aspects of the Concepts of Innovation and Innovation Activity]. Intellektual'naya sobstvennost'. promyshlennaya sobstvennost [Intellectual Property. Industrial Property], 2012, no. 2, pp. 5-12.

Demina M.A. Pravovoe regulirovanie nauchnoj i innovacionnoj deyatel'nosti medicinskih organizacij [Legal Regulation of Scientific and Innovative Activities of Medical Organizations]. Aktual'nye problemy rossijskogo prava [Actual Problems of Russian Law], 2018, no. 11, pp. 116-123.

Efimceva T.V. Problemy pravovogo opredeleniya ponyatiya innovacionnoj deyatel'nosti [Problems of the Legal Definition of the Concept of Innovation Activity]. Gosudarstvo i pravo [State and Law], 2012, no. 12, pp. 91-95.

Gohberg L.M., Ditkovskij K.A., Kuznecova I.A. et al. Indikatory innovacionnoj deyatel 'nosti: 2019: statisticheskij sbornik [Indicators of Innovation Activity: 2019: Collection of Articles]. Moscow, NIU VShE, 2019.376p.

Klavdienko V.P. Nalogovoe stimulirovanie innovacionnoj aktivnosti predpriyatij v Kitae [Tax Incentives for Innovative Activity of Enterprises in China]. Obshchestvo i ekonomika [Society and Economy], 2018, no. 7, pp. 39-50.

Kostenko V.V. Ponyatie «innovacii», «innovacionnaya deyatel'nost'» v rossijskom zakonodatel'stve [The Concept of "Innovation", "Innovative Activity” in Russian Legislation]. SeveroKavkazskij yuridicheskij vestnik [North Caucasian Legal Bulletin], 2012, no. 1, pp. 85-89.

Krohina Yu.A. Problemy nalogovogo regulirovaniya gosudarstvenno- chastnogo partnerstva vinnovacionnoj sfere [Problems of Tax Regulation of Public-Private Partnership in the 
Innovation Sphere]. Finansovoe pravo [Financial Law], 2012, no. 2, pp. 21-26.

Lajchenkova N.N. K voprosu o roli nalogovogo zakonodatel'stva $\mathrm{V}$ processe postroeniya innovacionnoj ekonomiki: osnovnye puti sovershenstvovaniya [On the Role of Tax Legislation in the Process of Building an Innovation Economy: The Main Ways of Improvement]. Leningradskij yuridicheskij zhurnal [Leningrad Law Journal], no. 2 (40), 2015, pp. 216-223.

Lapin A.V. Razvitie nacional'noj innovacionnoj sistemy kak obyazatel'noe uslovie tekhnologicheskih izmenenij i rosta proizvodstva [Development of the National Innovation System as a Prerequisite for Technological Changes and Production Growth]. Administrativnoe i municipal'noe pravo [Administrative and Municipal Law], 2018, no. 4, pp. 26-41.

Melenkin V.L. Realizaciya politiki importozameshcheniya kak factor aktivizacii innovacionnyh processov na regional'nom urovne [Implementation of Import Substitution Policy as a Factor to Enhance Innovation Processes at the Regional Level]. Ekonomika $i$ ekologiya territorial'nyh obrazovanij [Economy and Ecology of Territorial Entities], no. 3, 2016, pp. 116-121.

Kuklina E.A., Fedorkov A.I., Chzhu Syaocin, Sun' Yujsyu, Se Tyan'chen. Nalogovaya politika stimulirovaniya innovacionnoj deyatel'nosti organizacij v Rossii i Kitae: etapy razrabotki i problem realizacii [Tax Policy of Stimulating Innovation Activity of Organizations in Russia and China: Stages of Development and Problems of Implementation]. Upravlencheskoe konsul'tirovanie [Management Consulting], 2013, no. 6(54), pp. 48-60.

Osnovnye napravleniya byudzhetnoj, nalogovoj $i$ tamozhenno-tarifnoj politiki na 2019 god i na planovyj period 2020 i 2021 godov (utv.Minfinom Rossii, 02.10.2018) [The Main Directions of Budgetary, Tax and Customs-Tariff Policy for 2019 and for the Planning Period 2020 and 2021 (Approved by the Ministry of Finance of Russia, October 2, 2018)]. Access from Reference Legal System "KonsultantPlyus".

Pashkova D.A. K voprosu o ponyatii «innovaciya» v rossijskom prave [On the Issue of the Concept of "Innovation" in Russian Law]. Voprosy ekonomiki i prava [Issues of Economics and Law], 2017, no. 108, pp. 7-11.

Postanovlenie Pravitel'stva RF ot 24.07.1998 no. 832 «O Koncepcii innovacionnoj politiki Rossijskoj Federacii na 1998 - 2000 gody» [Decree of the Government of the Russian Federation of July 24, 1998 No. 832 “'On the Concept of the Innovation
Policy of the Russian Federation for 19982000"]. Rossijskaya gazeta, 1998, August 19, no. 158.

Postanovlenie Pravitel'stva RF ot 30.04.2009№ $372 « O b$ utverzhdenii perechnya tekhnologicheskogo oborudovaniya (v tom chisle komplektuyushchih $i$ zapasnyh chastej $k$ nemu), analogi kotorogo ne proizvodyatsya v Rossijskoj Federacii, vvoz kotorogo na territoriyu Rossijskoj Federacii ne podlezhit oblozheniyu nalogom na dobavlennuyu stoimost'» [Decree of the Government of the Russian Federation of April 30, 2009 No. 372 "On Approving the List of Production Equipment, Including Components and Spare Parts, for Which Equivalents Are Not Manufactured in the Russian Federation and on Which Imports Into the Russian Federation Are Not Subject to VAT']. Access from Reference Legal System "KonsultantPlyus".

Aganina R.N., Andreev V.K., Andreeva L.V. et al. Predprinimatel'skoe pravo: Pravovoe soprovozhdenie biznesa: uchebnik dlya magistrov [Entrepreneurial Law: Legal Support of Business: Textbook for Master Students]. Moscow, Prospekt Publ., 2017. 848 p.

Proekt Federal'nogo zakona № 344994-5 «Ob innovacionnoj deyatel'nosti $v$ Rossijskoj Federacii» (red., vnesennaya v GD FS RF, tekst po sostoyaniyu na 18.03.2010) [Draft Federal Law No. 344994-5 "On Innovation Activity in the Russian Federation" (as amended by the State Duma of the Federal Assembly of the Russian Federation, text as of 18.03.2010)]. Access from Reference Legal System "KonsultantPlyus".

StepanenkoD.M. Termin «innovaciya» kak kategorial'naya osnova sovokupnosti vzaimosvyazannyh ponyatij [The Term "Innovation" as a Categorical Basis of a Set of Interrelated Concepts]. Nauka Krasnoyar'ya [Krasnoyarsk Science], 2012, vol. 1, no. 1, pp. 65-74.

Stepanenko Yu.V. Perspektivy administrativnopravovogo regulirovaniya nauchnoj deyatel'nosti v svete razrabatyvaemoj Strategii nauchnotekhnologicheskogo razvitiya Rossii na dolgosrochnyj period [Prospects of Administrative and Legal Regulation of Scientific Activity in the View of the Forthcoming Strategy of Scientific and Technological Development of Russia for the Long-Term Period]. Administrativnoe pravo $i$ process [Administrative Law and Procedure], 2016, no. 9, pp. 5-12.

Taburchak A.P., Zelezinskij A.L., Kondrashova E.A. Issledovanie sushchnosti innovacionnoj deyatel'nosti [Research into the Essence of Innovation]. Zhurnal pravovyh i ekonomicheskih issledovanij [Journal of Legal and Economic Research], 2018, no. 4,pp. 204-208. 


\section{УПРАВЛЕНИЕ ЭКОНОМИЧЕСКИМ РАЗВИТИЕМ}

Trofimov S.V. O nalogovyh aspektah problemy importozameshcheniya $\mathrm{V}$ realiyah dejstvuyushchego zakonodatel'stva [On the Tax Aspects of the Problem of Import Substitution in the Realities of Current Legislation]. Zakonodatel'stvo i ekonomika [Legislation and Economics], 2015, no. 9, pp. 35-40.

Yakovlev G.I., Strel'cov A.V. Osobennosti formirovaniya promyshlennoj politiki i predprinimatel'stva v usloviyah rosta global'noj neopredelennosti [Features of the Formation of Industrial Policy and Entrepreneurship in the Context of Growing Global Uncertainty]. Biznes. Obrazovanie. Pravo [Business. Education. Law], 2020, no. 3(52), pp. 112-117.

Yankovskij, R.M. Pravovoe regulirovanie gosudarstvennoj podderzhki innovacij $\mathrm{V}$ Rossijskoj Federacii [Legal Regulation of State Support for Innovations in the Russian Federation]. Predprinimatel'skoe pravo [Entrepreneurial Law], 2017, no. 3, pp. 21-29.

Adams R., Bessant J., Phelps R. Innovation Management Measurement. A Review. International Journal of Management Reviews, 2006, no. 8 (1), pp. 21-47.

Andreoni A., Chang H.-J., Scazzieri R. Industrial Policy in Context: Building Blocks for an Integrated and Comparative Political Economy Agenda. Struct. Change Econ. Dyn., 2019a, no. 48, pp.1-6.

Andreoni A., Chang H.-J. Political Economy of Industrial Policy: Structural Interdependencies, Policy Alignment and Conflict Management. Struct. Change Econ. Dyn., 2019b, no. 48, pp. 136-150.

Blok V., Lemmens P. The Emerging Concept of Responsible Innovation. Three Reasons Why it is Questionable and Calls for a Radical Transformation of the Concept of Innovation. Koops B.-J., Oosterlaken I., Romijn H. Responsible Innovation 2: Concepts,
Approaches, and Applications. Cham, Springer, 2015, pp. 19-35.

European Commission. Communication from the Commission to the European Parliament, the Council, the European Economic and Social Committee of the Regions: A Renewed EU Strategy 2011-2014 for Corporate Social Responsibility. Brussels, [S. 1.], 2011.

Fichter K. Innovation Communities: The Role of Networks of Promoters in Open Innovation. R\&D Management, 2009, no. 39 (4), pp. 357-371.

Garcia R., Calantone R. A Critical Look at Technological Innovation Typology and Innovativeness Terminology: A Literature Review. Journal of Product Innovation Management, 2002, no. 19 (2), pp. 110-132.

Gassmann O., Enkel E. Towards a Theory of Open Innovation: Three Core Process Archetypes. Lissabon, R\&D Management Conference (RADMA), 2004, pp. 1-18.

Kieser A. Innovationen. Grochla E., Hrsg. Handwörterbuch der Organisation. Poeschel, Stuttgart, 1969, pp. 741-750.

Moldaschl M. Why Innovation Theories Make no Sense, Lehrstuhlpapiere. Professur für Innovationsforschung und Nachhaltiges Ressourcenmanagement, 2010, no. 9.

Chesbrough H., Vanhaverbeke W., West J., eds. Open Innovation: Researching a New Paradigm. Oxford, Oxford University Press, 2006.

Phillips R., Caldwell C.B. Value Chain Responsibility: A Farewell to Arm's Length. Business \& Society Review, 2005, no. 110 (4), pp. 345-370.

Schumpeter J.A. Business Cycles: A Theoretical, Historical, and Statistical Analysis of the Capitalist Process. New York, McGraw-Hill, 1939. $658 \mathrm{p}$.

Vedin B.A. Large Company Organization and Radical Product Innovation. Lund, Bratt-Institut für Neues Lernen, 1980. 
А.В. Шкаленко, Ю.А. Тымчук. Хозяйственные субъекты в условиях технологической модернизации

\section{Information About the Authors}

Anna V. Shkalenko, Candidate of Sciences (Economics), Associate Professor, Department of Marketing, Volgograd State University, Prosp. Universitetsky, 100, 400062 Volgograd, Russian Federation, lavra.ne@mail.ru, https://orcid.org/0000-0002-9505-9819

Yulia A. Tymchuk, Candidate of Sciences (Jurisprudence), Assistant Lecturer, Department of Civil and International Private Law, Volgograd State University, Prosp. Universitetsky, 100, 400062 Volgograd, Russian Federation, tymchuk@volsu.ru, https://orcid.org/0000-0002-0854-3179

\section{Информация об авторах}

Анна Викторовна Шкаленко, кандидат экономических наук, доцент кафедры маркетинга, Волгоградский государственный университет, просп. Университетский, 100, 400062 г. Волгоград, Российская Федерация, lavra.ne@mail.ru, https://orcid.org/0000-0002-9505-9819

Юлия Александровна Тымчук, кандидат юридических наук, ассистент кафедры гражданского и международного частного права, Волгоградский государственный университет, просп. Университетский, 100, 400062 г. Волгоград, Российская Федерация, tymchuk@volsu.ru, https://orcid.org/0000-0002-0854-3179 